\title{
A representação das minorias: análise do debate desenvolvido por Francisco Belisário Soares de Souza e José de Alencar
}

\author{
Maria Leticia Juliano Diniz Brito \\ 1 Mestranda em Ciência Política na Universidade de São Paulo- USP, Brasil. E-mail: mariazinha_juliano@hotmail.com
}

\begin{abstract}
RESUM 0: 0 artigo analisa as concepções formuladas na segunda metade do século XIX por dois intelectuais brasileiros, Francisco Belisário Soares de Souza e José de Alencar, sobre a representação política das minorias, principalmente no que concerne ao sistema proporcional como mecanismo eleitoral. Além disso, recorreremos a outros intelectuais, como John Stuart Mill, uma vez que a discussão elaborada por esse autor serviu de base para o debate que estava sendo construído no Brasil. A despeito de existir um consenso sobre a necessidade de todos serem ouvidos e representados adequadamente, os autores não tinham uma opinião única sobre qual seria o melhor mecanismo para que a representação das minorias fosse assegurada.

Palavras-chaves: Francisco Belisário Soares de Souza, José de Alencar, Representação das minorias, Sistema proporcional.
\end{abstract}

\section{The Representation of minorities: the debate developed by Francisco Belsário Soares de Souza and José de Alencar}

ABSTRACT: The article analyzes the concepts formulated in the second half of the nineteenth century by two Brazilian intellectuals, Francisco Belisário Soares de Souza and José de Alencar, about the political representation of minorities, especially with regard to the system of proportional representation as an electoral mechanism. In addition, we will resort to other intellectuals, such as John Stuart Mill, because the discussion proposed by this author was the basis for the debate that was being developed in Brazil. Despite there being a consensus about the necessity of everybody to be heard and adequately represented, the authors did not have a single opinion on what would be the best mechanism for minority representation.

Keywords: Francisco Belisário Soares de Souza, José de Alencar, Representation of minorities, Proportional representation

\section{INTRODUÇÃO}

A necessidade de representação das minorias no Brasil da segunda metade do século XIX era uma tese de modo geral bem aceita no campo da teoria, mas ainda muito controversa no terreno prático; 0 debate e principalmente as melhores maneiras de assegurar que as opiniões de todos fossem garantidas não tinham um consenso (SOUZA, 1979) ${ }^{1}$.

\footnotetext{
${ }^{1}$ Apesar da questão da representação da minoria já estar em pauta e ser motivo de preocupação dos legisladores desde a lei de 1846, havia ainda opiniões contrárias a ela e que apoiavam que o governo representativo devia ter o seu funcionamento baseado exclusivamente na vontade da maioria. Por exemplo, em 9 de agosto de 1860, o senador Silveira da M otta, ao defender que a eleição devia ser a partir de sistemas majoritários,
} 
A idéia que estava por trás da defesa da representação das mionorias era a de que os governos representativos tinham um grande defeito que precisava ser controlado: o de ter o seu funcionamento baseado exclusivamente nas vontades da maioria, deixando consequentemente uma parte da população sem voz participativa nas decisões. 0 grande problema, portanto, estava nos métodos utilizados para a seleção de representantes e participação política. De acordo com John Stuart M ill (1981, p. 74)., era preciso achar um modo de modificar esta situação, pois "Sem isto, não será possível uma verdadeira democracia - haverá apenas uma falsa aparência de democracia". 0 desafio era o de fazer com que as minorias passassem a ser representadas, sem que isso interferisse nos aspectos benéficos da democracia.

Diante dessas considerações, foram propostos vários expedientes por meio dos quais esses males poderiam ser eliminados ou pelo menos amenizados. No Brasil, assim como em outros países, essa questão também estava em pauta, e ela se fez tanto no campo político, quanto no intelectual. A busca por formas que permitissem a minoria uma representação mais adequada pode ser encontrada nos debates eleitorais que se sucederam ao longo do Império, tanto quanto nos debates de escopo mais teórico promovidos por pensadores da época. Embora Francisco Belisário Soarez de Souza e José de Alencar tenham sido políticos, eles também podem ser considerados exemplos de pensadores, uma vez que se dedicaram a pensar e analisar as questões eleitorais e a organização do sistema político brasileiro.

Dito isso, este trabalho pretende examinar as concepções formuladas por esses dois grandes teóricos do período, sobre a representação política das minorias, principalmente no que concerne ao sistema proporcional como mecanismo eleitoral.

Para tanto, buscaremos, na medida do possível, indicar e avaliar como Souza no seu estudo sobre o Sistema Eleitoral do Império de 1872, e Alencar em seus escritos sobre 0 Sistema Representativo de 1868 e sobre a Reforma Eleitoral de $1874^{2}$ apresentam essa temática e os meios possíveis de assegurarem voz às minorias. Além disso, recorreremos a outros intelectuais, como John Stuart Mill, uma vez que a discussão elaborada por esse autor serviu de base para o debate que estava sendo construído no Brasil.

dizia que: "O princípio fundamental que deve regular a eleição dos representantes, é que deve ela ser o produto da maioria; só a maioria é que dá o direito de representar: este é o nosso princípio. Pois quando nós admitimos este princípio, como havemos, sem faltar a lógica, é admitir que por impedimento daquele que tem a maioria venha interinamente ao parlamento um representante de uma opinião vencida representar 0 que? Alguém no parlamento diz ao país que representa a minoria?" (ANAIS DO SENADO, 1860: 116). Segue a mesma opinião o liberal Paula Souza. Ele foi o primeiro que se pôs contrário à lei que propunha suplências de deputados como modo de representar a minoria, não porque seria um mecanismo inadequado para esse fim, mas porque em sua visão, esse princípio parecia na verdade repugnar o sistema representativo, que devia ser o da maioria. Dois anos depois, entretanto, como salientado por Souza (1979), o seu discurso passa ganhar um novo tom: "uma minoria, que pode ser maioria num terço da província, pode não aparecer no parlamento, e isto, é um mal muito sério".

2 Este trabalho tomará as ideias sobre representação política de José de Alencar, a partir do ensaio produzido por Wanderley Guilherme dos Santos. 
Com o objetivo de apresentar a temática desenvolvida pelos intelectuais, optou-se por percorrer primeiramente a parte teórica do argumento, para depois ser introduzido a parte prática da discussão, que seria o debate sobre os mecanismos que podem ser adotados com a finalidade de assegurar a representação das minorias.

Na primeira parte do texto, será apresentada em linhas gerais a discussão feita por Souza, Alencar e Mill sobre como na democracia e nos governos democráticos se põe o problema da representação política e das minorias e quais são as suas possíveis consequências, para que em um segundo momento sejam discutidas algumas propostas para que minorias políticas também possam ser representadas. Feito esse reconhecimento, o sistema de representação proporcional será então examinado.

\section{REPRESENTAÇÃO DAS MINORIAS}

$\mathrm{Na}$ democracia representativa prevalece a força do maior número de pessoas, maioria, sobre a força do pequeno número, minoria. Isso porque, segue-se o princípio de que os interesses do maior número de pessoas devem ser preferidos aos do menor número, acarretando a vulnerabilidade desta diante das decisões tomadas pela maioria. Como proposto por Tocqueville (1987, p.190), “É da própria essência dos governos democráticos que o império da maioria seja absoluto pois fora da maioria, nas democracias, não existe coisa alguma que subsista". Diante desse cenário, como ficam as minorias?

John Stuart Mill (1981), um grande teórico sobre a questão das minorias, observa que um dos grandes perigos da democracia está na possibilidade de uma única classe participar do poder e legislar somente ao seu favor em detrimento do restante da população. Assim, ele afirma:

Um dos maiores perigo, portanto, da democracia, bem como de todas as outras formas de governo, consiste nos interesses sinistros dos detentores do poder; é o perigo da legislação de classe; do governo que visa (com sucesso ou não) o benefício imediato da classe dominante, em perpétuo detrimento da massa (MILL, 1981: 68).

Para Mill (1981), a minoria ser adequadamente ouvida é parte essencial da democracia, sem isso, há apenas uma falsa aparência de igualdade. Em uma democracia igual, todos devem ter o direito de serem representados assegurado, por isso, os partidos, não importando qual sejam, devem receber poder correspondente, nunca superior, a sua proporção de eleitores. "Uma maioria de eleitores deveria sempre ter uma maioria de representantes; mas uma minoria de eleitores deveria sempre ter uma minoria de representantes." (MILL,1981: 72)

José de Alencar (1991) também sente desconforto com o modo como os cargos políticos são distribuídos e por isso repudia o princípio fundamental do governo democrático representativo: o que se baseia na vontade da maioria. Na atualidade, a- 
lém do alargamento dos limites do estado que impossibilitam a reunião de toda a população em um comício em praça aberta, o homem também está mais envolvido com o seu mundo privado, o que o impede de se ocupar assiduamente da vida pública. A democracia, com o desenvolvimento da vida civil, teve que assumir a forma indireta. Por isso, diferentemente das democracias diretas do passado, em que "o homem era exclusivamente cidadão", hoje o povo precisa exercer o poder por mandatários (ALENCAR, 1991):

\begin{abstract}
A nação ou uma parte dela elege os homens que devem exercer a porção de soberania necessária para a direção do Estado. Essa eleição vence-se em escrutínio à maioria absoluta ou relativa de votos. 0 domínio exclusivo da maioria e a anulação completa da minoria; eis portanto o pensamento iníquo e absurdo sobre que repousa atualmente o governo representativo. (ALENCAR, 1991:14).
\end{abstract}

A partir desse pressuposto, Alencar (1991) argumenta que se pelo princípio majoritário a maioria monopoliza a soberania do povo, ela também teria o poder, e nada a impede de fazer, para reprimir e coagir a minoria. 0 que se tem, na realidade, é um governo equivocadamente chamado de democracia, mas que se baseia na opressão de um grupo pelo outro, em virtude da vil razão do número.

Para ele, a democracia representativa deve valer-se da fórmula que existia na origem da democracia: "O governo de todos por todos e a independência de cada um por si mesmo" (ALENCAR, 1991: 25). Isso significa dizer que, se nos tempos modernos não é mais possível ter uma democracia direta, é preciso que, no entanto, os princípios do governo popular estejam presentes no parlamento. Ele dirá:

É essencial à legitimidade dessa instituição que ela concentre todo país no parlamento, sem exclusão de uma fração qualquer de uma opinião pública. Na representação, como no comício do qual ela deva ser a cópia fiel, cumpre que todas as convicções tenham voz; todos os elementos sociais um órgão para defender as suas ideias (ALENCAR, 1991:37).

A formação do corpo legislativo não deve ser expressada via maioria, pois o uso desse tipo de regra nas eleições tira da minoria o direito de exercer a sua porção correspondente no poder. Quando há no parlamento uma representação proporcional de todas as correntes de opinião existentes no demos, é possível que ideias divergentes sejam confrontadas. 0 governo de todos por todos não significa homogeneidade, Alencar (1991) compreende que é impossível na sociedade humana haver uma única opinião, mas ele propõe que do embate no congresso entre vozes discordantes e de posições divergentes, 0 alvitre que obtiver o maior número expressará a vontade universal, porque todos participaram.

A justiça exige que o todo seja representado para a formação da soberania. 
(...) Em suma, o ideal de governo é que a democracia se realize no parlamento por meio da representação com o mesmo caráter integral da democracia originária, impossível na atualidade (ALENCAR, 1991:46-47).

A minoria não ficou de fora deste debate, mas ela também concorreu para a formação dessa soberania ao trazer para a discussão uma posição contrária da maior parte dos representantes, assim: todos foram obrigados a ouvirem e a analisarem a questão sob outros olhos. Alencar afirmará:

A soberania nacional não significa uma soma de vontades ou o produto da adição de certa quantidade de votos; é um poder indiviso que emana da totalidade do país; uma vontade máxima e plena formada pela concreção das vontades. Todos concorrem para ela; ninguém isoladamente a criou (ALENCAR, 1991: 26).

Sendo assim, pode-se dizer que para Alencar (1991), a maioria, pode ser recorrida como um instrumento somente diante de decisões, pois ela não exerce qualquer poder e não funciona como governo; é apenas um meio material para a manifestação da soberania nacional. Logo, para este autor, um país que assenta o princípio da representação na sua base racional, será um lugar mais democrático, pois não haverá homens sofrendo o julgo indecoroso de outros, haverá sim homens submetendo-se à opinião geral, à soberania para a qual concorreu com suas ideias.

Francisco Belisário Soarez de Souza (1979) segue nesse mesmo sentindo. Para expor o seu raciocínio, ele se apoia na argumentação feita por Aubry Vitet, o qual afirma que para se entender o problema das minorias em uma democracia é preciso ter em mente duas diferenças: (1) o direito de representação e 0 (2) direito de decisão. No primeiro caso, o que deve prevalecer é a proporcionalidade, pois todos nós devemos ter 0 direito de sermos representados, de ter alguém que delibere e opine por nós, em prol dos nossos interesses. Já no que se refere ao segundo ponto, quando uma assembleia precisa decidir qualquer assunto, o que deve vigorar é a vontade da maioria, já que esse é o único meio possível para se chegar a um resultado viável e plausível.

Pelo sistema adotado no período, de acordo com Souza (1979), apenas as maiorias chegam ao poder, fazendo com que possivelmente muitas províncias mandassem durante anos ao parlamento políticos de uma única opinião. Por exemplo, se houvesse dois candidatos de partidos diferentes em certa província e um recebesse 1000 votos e o outro 900, o primeiro iria ganhar o cargo, por ter conquistado a maior votação, enquanto o segundo grupo não mandaria nenhum representante, portanto uma parte seria ouvida, enquanto a outra, mesmo sendo proporcionalmente relevante, não teria quem a defendesse e advogasse por suas causas.

Souza (1979) narra que quando discussão semelhante foi feita na Inglaterra, William Gladstone (1809-1898), líder dos liberais, objetou na Câmara dos Comuns que as minorias eram representadas pela divisão do país em pequenos distritos, e se em um 
distrito predominava sempre um partido, em outra localidade, outro partido teria superioridade. Souza (1979) defenderá que esse mecanismo não é suficiente para levar a representatividade das minorias ao Parlamento. Recorrendo mais uma vez ao exemplo dado acima: os 900 indivíduos da segunda província que foram vencidos nas urnas não se sentirão compensados e ouvidos pelo fato que em outra província um correligionário do seu partido tenha sido eleito. Esse político, mesmo sendo do mesmo partido, não necessariamente tem os mesmos interesses e pretensões que o candidato vencido.

O menor nível de debate em consequência da sub-representação ou mesmo ausência de representação de minorias político-eleitorais é para Souza um grande mal, pois impede que a minoria seja escutada. Para ele, é justamente através delas, a partir da defesa por um pequeno número de partidários - até serem abraçadas por todos - que as grandes conquistas sociais são alcançadas.

Além do malefício às minorias que o sistema vigente na época impunha, o autor faz outra advertência em relação a isso, salientando que constitui um benefício para a sociedade o debate e que é melhor dar espaço para que a minoria seja ouvida e assim, caso suas proposições sejam nocivas repugná-las, do que deixar que essas ideias sejam renegadas entre as camadas inferiores da população à espera de uma comoção geral para que frutifiquem e dominem. Dessa maneira, permitir que as divergências tenham meios de se manifestar não seria apenas uma questão de justiça, mas uma conveniência social contra possíveis ataques surpresas de ideologias até então desconhecidas.

Para Souza (1979), o papel do parlamento, portanto, não deve ser o de apenas propor questões para serem votadas sem que haja qualquer tipo de discussão e esclarecimento, deve, na verdade, ser um local onde as opiniões sejam ouvidas e confrontadas para que se chegue a melhores conclusões. Sendo assim, a representação em uma assembleia não pode ser exclusiva da maioria, já que isso encerra uma grave injustiça e até mesmo um perigo social. "A maioria deve governar, mas a maioria só se forma pela discussão e para uma discussão regular é necessário ouvirem-se todas as opiniões". (Souza, 1979: 143).

Souza (1979), como já ressaltado, concorda que no momento das votações em uma assembleia é por meio da força do maior número que são feitas as decisões, mas compreende que se há a representação de todas as opiniões, então se chegará, por meio do confronto e exame de razões opostas, à verdade.

Mill (1981) compreende que em um corpo legislativo, que realmente delibera, a maioria deve sim prevalecer sobre a minoria e a decisão da maior parte deve ser acatada por todos, mas, diferentemente de Souza e Alencar, adverte que mesmo em uma democracia na qual todos sejam representados em sua devida proporção e onde exista a igualdade, a imparcialidade e o 'governo de todos por todos' não estaria livre do poder da maioria no momento de legislar e administrar.

Além disso, como a grande maioria dos eleitores em todos os países são constituí- 
dos de trabalhadores manuais, haveria ainda outro perigo a ser sanado: 0 do baixo nível de inteligência política. As leis do país estariam sujeitas aos males e desejos de uma única classe, a dos menos instruídos, sendo que o único freio para esta tirania seria a sua tolerância e o seu bom senso, que não são suficientes como garantia.

Mas então, como evitar que a força do maior número, dos não instruídos, abuse deste poder? A limitação do sufrágio em sua visão não é um meio eficaz, uma vez que acarretaria uma exclusão compulsória de parte da população de seu direito à representação. 0 autor é favorável ao sufrágio universal, pois, primeiro, em um governo representativo é justo que todos possam ter voz na condução dos assuntos que lhes interessam, e em segundo lugar, ele acredita que quando as questões públicas são levadas às classes mais baixas da população, estas são obrigadas a pensar e a se instruir, tornando-se membros conscientes da grande comunidade.

Entretanto, apesar deste seu posicionamento, é preciso assinalar que Mill avalia que algumas exclusões devem ser feitas: os analfabetos, as pessoas pouco instruídas as pessoas que não pagam impostos, as que recebem ajuda financeira oficial, e as que tenham falido em seus negócios deveriam ser privadas do direito de voto.

A solução advogada pelo filósofo para este fim é o de admitir um peso maior para os sufrágios daqueles cujas opiniões merecem maior consideração por possuir uma capacidade superior para a direção dos assuntos públicos. Em outras palavras, isso significa dizer que os votos das pessoas com níveis mais elevados de instrução teriam um peso maior do que os das pessoas comuns. A ideia que está por trás disso é a de que os indivíduos com mais estudo/educação formal têm um melhor discernimento para tomar as decisões e que devido a isso, os seus pareceres, e até mesmo os seus desejos, merecem consideração maior. ${ }^{3}$

De acordo com M ill (1981), este mecanismo, nomeado como 'voto plural', não se contrapõe ao princípio da representação proporcional, tendo em vista que não exige de nenhuma pessoa o sacrifício completo de sua própria opinião. A este respeito, ele dirá:

Não ter nenhuma voz naquilo que ao menos em parte lhes diz respeito, é algo a que as pessoas não se submetem voluntariamente; mas quando 0 que Ihes diz respeito, diz respeito também a outras pessoas que entendem melhor do assunto, ver a opinião destas últimas contar mais é algo que as pessoas esperam, e que vai de acordo com a marcha natural de todos assuntos da vida humana (MILL, 1981:93)

Sobre quais seriam os critérios para conferir esta superioridade, o inglês apenas levanta algumas sugestões, já que ainda não tem certeza de quais seriam as melhores

\footnotetext{
${ }^{3}$ Como se verá adiante, Mill irá defender que o mecanismo do voto proporcional também oferece meios para que os representantes com qualidades intelectuais sejam eleitos para o Congresso, porém, como defendido por ele, este grupo ainda seria uma minoria e mesmo que ele seja ouvido e que suas opiniões sejam levadas em consideração devido a sua reputação e influência, isso não seria suficiente para eliminar o poder de uma maioria sem instrução. Por isso, o autor buscou outra alternativa que pudesse auxiliar nesta finalidade.
} 
estratégias a serem adotadas. Entre as possibilidades aventadas por ele está o aferimento a partir das ocupações que cada um possui e/ ou por meio de provas aplicadas em universidades ${ }^{4}$.

Entretanto, constitui um requisito absoluto que este mecanismo não influa na proporcionalidade de representações existentes no parlamento. A pluralidade de votos deve ser um modo para se evitar que as pessoas não instruídas legislem em proveito da sua classe, mas também não deve permitir que as pessoas com instrução exerçam um mandato em prol de sua classe.

Da mesma forma que Mill, Alencar também é favorável à extensão do sufrágio e afirmará, como já salientado, que a legitimidade do poder político está na delegação indivisa da soberania por todos e que, portanto não haveria como estipular barreiras à entrada na sociedade política. A exclusão de qualquer indivíduo implica a eliminação de todos os direitos sociais e neste ponto, os dois autores divergem um pouco, pois para Alencar todos os membros da comunidade política estariam qualificados para votar, sem qualquer tipo de restrição, independentemente de cor, condição 0cupacional, sexo ou renda.

Todo o sistema eleitoral repousa sobre esse dogma da universalidade do voto. 0 membro de uma comunhão política, qualquer que seja seu estado e condição, tem em si uma molécula de soberania e deve concorrer com ela para o governo de todos por todos. Trata-se de um direito natural, originário, derivado do dogma da igualdade (ALENCAR apud SANTOS, 1991: 22, 25, $26,42,44)$.

Alencar ainda irá se opor a Mill em relação ao temor da tirania dos menos instruídos, pois acredita que não existe este perigo; para ele, na verdade, todos devem ter os mesmos direitos e de forma igual, caso contrário a soberania não será perfeita. 0 perigo, portanto, está na não concessão dos direitos políticos a todos.

Portanto, o mais rico, o mais sábio, o maior proprietário, tem um voto superior ao que for menos. A mesma razão com que se priva ao proletário do sufrágio, não tolera a igualdade jurídica entre indivíduos de capacidade desproporcional. (...) O poder político é um e indiviso; é a delegação da soberania universal (ALENCAR apud SANTOS, 1991:84-85).

\section{MECANISM OS DEFENDIDOS EM PROL DAS MINORIAS}

Mas como assegurar a representação das minorias? As divergências de opiniões naquele período sobre quais seriam os melhores sistemas eram grandes, cada um tinha uma proposta diferente e o consenso nesse campo não era tarefa fácil. Havia

\footnotetext{
${ }^{4}$ M ill deixa claro que a riqueza não deve ser utilizada como requisito de superioridade, pois, apesar de muitas vezes este critério estar relacionado com o grau de educação, ele não é perfeito e traz por isso muitas desvantagens.
}

PRACS: Revista Eletrônica de Humanidades do Curso de Ciências Sociais da UNIFAP 
até mesmo os que acreditavam que nenhum meio seria suficiente, como Paulino de Souza.

Na sessão da câmara do dia 22 de julho de 1870, 0 então ministro do Império, após citar várias propostas de representação da minoria levantadas na Inglaterra, irá fundamentar o seu projeto de reforma eleitoral da seguinte forma:

0 sistema das minorias é realmente engenhoso, mas dando ocasião o manejo que triufam da vontade dos eleitores, não o posso aceitar, quando o meu fim é a verdade de representação e não adestrar ainda mais os partidos aos estratagemas eleitorais. Demais, Sr. Presidente, nem o voto incompleto, nem o cumulativo, nem o complementar ou o quociente eleitoral que tanto modifica na forma de sistema das minorias, tem por ora assentado em meios práticos capazes de surtir os desejados efeitos, ainda quando 0 plano seja bom em teoria (SOUZA apud SOUZA, 1979:138).

Entre os meios propostos estavam o voto cumulativo e o incompleto. Em junho de 1860, o deputado Sérgio de Macedo ocupou-se desse aspecto em seu discurso na sessão da câmara do dia 21 ao tratar de um sistema singular de representar as minorias, como ele próprio caracteriza, proposto por Grath Marshal em uma carta de 1853 a lord John Russell. 0 sistema consistia em dois arbítrios: o primeiro era 0 do voto incompleto, que estabelecia que os eleitores votassem em um número menor de candidatos do que o número de vagas que o colégio eleitoral iria eleger, por exemplo, se em um colégio eleitoral tinha direito a três deputados, o eleitor só poderia listar dois nomes, assim, a maioria seria representada pelos dois candidatos mais votados e a minoria concentraria o seu voto no terceiro nome, o que evitaria que um único partido elegesse todos os candidatos do distrito.

0 segundo arbítrio era 0 do voto cumulativo, que é a possibilidade do eleitor votar mais de uma vez em um mesmo candidato: se um eleitor tem direito de dar três votos, pois naquele distrito se elegem três deputados, ele poderia então depositar os seus três votos em nomes diferentes ou em um mesmo nome e neste último caso, contará para o candidato três votos. Essa premissa permitiria ampliar as chances da minoria, caso ela combinasse de votar em um único candidato. De acordo com $\mathrm{Ma}$ cedo, tudo isso tem isso rejeitado como utopia.

Segundo Souza (1979), o sistema mais difundido era o da representação proporcional ou do quociente eleitoral. Na década de 1850 dois homens, um desconhecido do outro, criaram quase ao mesmo tempo esse sistema, o inglês Hare e o dinamarquês Andrae. A ideia básica que está por trás do seu funcionamento é a de assegurar uma melhor distribuição do poder, sem favorecer um grupo em detrimento de outro: todos recebem a real parte que lhe cabe, de acordo com o seu tamanho. E como isso é garantido? A representação parlamentar (o número de cadeiras) é diretamente determinada pelo número de votos obtidos. Para explicar esse mecanismo, parte-se mais uma vez da argumentação de Aubry Vitet: 
Sendo os distritos divididos de modo que nomeiem certo número de deputados, cada eleitor deve inscrever na sua cédula tantos nomes quanto são os representantes que se vão eleger no distrito; inscreve-se por ordem de preferência; todavia a cédula nunca pode, em caso algum, valer por mais de um voto. Terminado o escrutínio, divide-se o número de cédulas pelo número de deputados a eleger. 0 resultado da operação é o número necessário, e quanto estritamente basta o candidato obter para que seja eleito. É o que chamamos quociente eleitoral. Fixado este algarismo fundamental, conta-se em cada cédula o primeiro nome. Apenas um candidato chega ao quociente exigido, é proclamado eleito, e as cédulas que o elegeram ficam sem valor; depois, se em alguma das cédulas seguintes vem em primeiro lugar o nome daquele candidato, é riscado, e só se conta o nome do candidato que está em seguida. Prossegue-se o mesmo processo até que se esgotem as cédulas, até que cada uma delas tenha contribuído para eleger um deputado. (VITET apud SOUZA, 1979:146).

Entre os que apoiavam, na Inglaterra, esse mecanismo estava Mill. Para ele, o modelo proposto por Thomas Hare garantiria uma proporcionalidade representativa sem que se perdessem os benefícios da democracia. 0 autor em questão chega a afirmar que esse projeto traz tantas vantagens que, a seu ver, ele pode ser situado entre as maiores melhorias feitas na teoria e na prática do governo.

Em sua visão, além da possibilidade de que todos fossem adequadamente representados e ouvidos, esse mecanismo permitiria que houvesse um maior laço entre os eleitores e os políticos; estes saberiam o motivo de terem sido eleitos e poderiam apresentar no parlamento os valores e interesses de seu eleitorado.

Mais um ponto levantado entre outros, é de que o esquema de Hare possibilitaria elevar o nível intelectual do corpo legislativo, isso porque, os homens capazes e com grandes qualidades, que antes não conseguiam se eleger, agora teriam chances de chegar no número necessário para completar o quociente eleitoral. Para Mill (1981), este ponto é muito importante, pois como a tendência natural do governo representativo é a mediocridade coletiva, que é intensificada pelas extensões do direito eleitoral que coloca o poder nas mãos de classes cada vez mais abaixo do nível de instrução da comunidade, faz muita diferença que um sistema consiga selecionar candidatos com caracteres superiores.

Mill (1981) admite que os representantes instruídos ainda assim seriam a minoria, mas apesar do seu pequeno número, eles teriam grande influência nos debates por conta dos seus argumentos consistentes e poderiam por isso até mesmo levar a maioria intelectualmente menos dotada a rever os seus posicionamentos. Portanto, a maioria não teria força para legislar da forma que simplesmente lhe conviria, já que a minoria capaz funcionaria como um peso no momento das decisões.

Mas se puder ser garantida a presença na Assembleia Representativa de pelo menos algumas melhores cabeças do país, embora o restante consista apenas de inteligências medianas; a influência destas mentes privilegiadas 
se faria fortemente sentir nas deliberações gerais (...). Não consigo conceber outra maneira de garantir tão positivamente a presença de tais mentes quanto no sistema proposto pelo Sr. Hare. (MILL, 1981:79)

De acordo com Souza (1979), apesar de todas estas questões sobre o voto proporcional ainda serem novas no período em que escreve, elas já eram largamente discutidas e estavam até mesmo consagradas na legislação eleitoral de alguns países. Contudo, no Brasil, não se pode dizer o mesmo; aqui essa ideia foi apresentada com certa precocidade, mas ainda causava muita estranheza.

Em 1848 circulou em Pernambuco um panfleto escrito por Ignácio de Barros Barreto Júnior, na época estudante de direito, com o seguinte título: M emória acerca de um novo sistema de organização do governo representativo, no qual se expunha a doutrina da representação das minorias por meio do sistema eleitoral proporcional. De acordo com o panfleto, a maioria, no sistema de eleição adotado naquele período, tinha a possibilidade de usurpar o direito da minoria de ter os seus interesses sociais apreciados; para que houvesse de fato a representação de todos os grupos, era preciso que os cargos políticos fossem distribuídos proporcionalmente entre todos.

Uma província ou antes um dos círculos de alguma província, compondo-se de três interesses, ou partidos, ou individualidades (como lhe quiserem chamar) e um desses partidos de 500 votantes, e outros de 300, e o terceiro de 100; esse círculo somente seria representado perfeitamente, isto é, segundo a importância e a natureza de cada um de seus partidos, se a representação desses círculos contasse de três grupos de representantes, estando esses grupos entre si, a respeito da importância de cada um deles, na mesma razão das dos seus representados entre si. (BARRETO apud SOUZA, 1979:140).

Segundo Souza (1979), as asserções feitas por Barros Barreto acabaram esquecidas no tempo, de modo a fazer acreditar que José de Alencar seria o primeiro a sugerir no Brasil a teoria da proporcionalidade como meio de solucionar o problema das minorias. Alencar foi aqui um dos que defendeu com grande vigor os princípios desse tipo de representação, cabe salientar que os seus primeiros artigos sobre 0 assunto foram publicados em 1859 no Jornal do Commercio, no mesmo ano que Stuart Mill editava o seu livro Thoughts on Parlamentary Reform e dois anos antes de Considerations on Representative Government.

Mas foi somente em 1868 e 1874 que a teoria de Alencar sobre a representação política ganhou maior fôlego com a publicação de Sistema Representativo e de Reforma Eleitoral, respectivamente. Deve-se a Wanderley Guilherme dos Santos o mérito de trazer à tona para a atualidade esses dois textos ao reuni-los e fazer um estudo crítico sobre essas obras. (RIZZO:2007).

Apesar de não ter sido o primeiro a sugerir uma solução pela proporcionalidade, Santos procura mostrar a singularidade do pensamento de Alencar, mas sem perder 
de vista as teorias que estavam sendo produzidas sobre a representação de minorias, principalmente aquelas advogadas por Mill. Pode-se dizer, portanto, que uma das intenções de Santos ao publicar o seu texto foi o de apresentar onde estava a originalidade dos esforços feitos por Alencar na defesa de um modelo de democracia.

A comparação feita por Santos entre esses dois autores não é arbitrária, mas ela está em consonância com a argumentação desenvolvida pelo próprio Alencar. Primeiro porque o momento político do Segundo Império brasileiro não era muito diferente do rotten system britânico em que escrevia Mill. Os ambientes sociopolíticos em que eles escrevem, de acordo com Santos, são de reduzidíssima participação, com grande quantidade de barreiras à entrada, de fraudes, corrupção, intimidação e de escassa institucionalização política. Além disso, apesar dos primeiros escritos políticos de Alencar (1859) serem anteriores a Considerations on Representative government, Sistema Representativo está em diálogo direto com o debate que está sendo construído por M ill. Mas, sobre isso, Santos deixa claro:

Fundamental, contudo, é que, mesmo supondo terem sido as Considerations a inspiração próxima de 0 Sistema, esse é um livro muito mais complexo e, digamos assim, mais 'metafísico' do que aquele. Não propõe um argumento somente sobre o governo representativo, mas sobre a origem do governo e da sociedade, pois só desta maneira Alencar considera possível justificar um especial tipo de sistema representativo - que é proporcional (SANTOS, 1991: 14).

Assim como Mill, Alencar (1991) defende que a representação proporcional traz diversas vantagens. Além de ser uma resposta para o problema das minorias, também (1) garante um governo de sumidades, (2) evita o espírito de facção e (3) cria, na sociedade, focos de resistência à ação da maioria ou do poder de um modo geral. (RIZZO: 2007).

$\mathrm{Na}$ avaliação de Souza (1979), esse sistema tem inegavelmente muitas vantagens, como percebe Mill e Alencar, mas ele não deixa de observar que também pode acarretar certos inconvenientes e injustiças graves. Isso porque há sempre a possibilidade de nenhum partido reunir uma maioria capaz de governar, em outras palavras, como o autor comenta "(...) as maiorias parlamentares poderiam ser tão diminutas, que qualquer governo estaria sempre em crise, à mercê dos despeitos dos seus correligionários e das coligações destes com os grupos oposicionistas". (SOUZA, 1979:147).

Portanto, diante desse panorama, na concepção de Souza (1979), o instrumento mais eficiente naquele período para assegurar a entrada de representantes da minoria na câmara dos deputados seria o voto incompleto. Ele não especifica por quais motivos tem essa preferência, apenas deixa claro que este sistema seria o mais eficiente e o que traria menos desvantagens.

No início da década de 1870, quando a Câmara dos Deputados discutia uma nova lei eleitoral, a questão dos direitos da minoria era um dos elementos ainda em pauta. 
No Brasil o sistema proporcional foi proposto em 1870 na sessão de 13 de agosto pelo deputado Mendes de Almeida, apesar da questão já ter aparecido em discursos anteriores. Em um relatório lido por José Bonifácio de Andrada e Silva em uma sessão da câmara em 1864, por exemplo, já havia ideias condizentes com esse sistema:

Concluirei as minhas observações acerca deste assunto manifestando que sigo a opinião dos que entendem que a justiça social exige que o direito de representação seja sempre assegurado em justa proporção às minorias numéricas. Se no governo representativo, o voto das maiorias deve a todos os respeitos prevalecer, não se segue daí que lhe compita o direito de privar as minorias de serem ouvidas no parlamento, e de exercerem, na parte que Ihes deve caber, a influência que Ihes resulta do direito de representação (SILVA apud SOUZA, 1970: 137).

Entretanto, naquele período houve certo receio do seu emprego, os seus 20 anos de existência (desde a primeira formulação feita por Hare) não foram suficientes para dar ao Legislativo a coragem para aceitá-lo como um novo sistema eleitoral. A Câmara do Império, após muito discutir, resolveu adotar em 1875 o sistema conhecido por Lei do Terço, que emprega o voto limitado como meio de evitar que a maioria fosse a governante soberana.

No Brasil, apesar de o voto proporcional ser preconizado e debatido precocemente, o sistema eleitoral proporcional só foi adotado na lei eleitoral de 1933.

\section{CONSIDERAÇÕES FINAIS}

A história das teorias e das instituições da representação política é um trajeto constituído por diversas tentativas de compreender a temática das maiorias vs. minorias. Conforme já observado, essa procura pelas variáveis explicativas de como está estruturado a representação política nos governos democráticos está associada aos temores suscitados pela busca de uma maior igualdade política.

Ao analisar a questão da minoria, a maior parte da literatura, iria buscar meios de evitar ou de pelo menos amenizar os efeitos da tirania da maioria. Diante desse debate, diversos mecanismos foram sugeridos, como o proporcional, o voto incompleto e 0 limitado.

No Brasil Império, em certa medida, houve um consenso, conforme salientou Souza (1979), da necessidade de fazer com que todos fossem ouvidos e representados adequadamente, mas na esfera prática não existiu uma única opinião. Isso pode ser percebido no debate desenvolvido por Souza e Alencar, como mostrado nesse trabaIho: ambos concordavam que no governo representativo havia uma soberania da maioria e que isso devia ser mudado, mas eles tinham pontos de vistas diferentes sobre qual seria o melhor modo de se fazer isso. Para o primeiro, apesar das diversas vantagens do método proporcional, o voto incompleto, naquele momento, seria 0 mais desejável, enquanto para o segundo, seria o proporcional. 
0 estudo desenvolvido neste trabalho apenas pretendeu levantar os pontos mais significativos dos dois autores sobre esse assunto; deve-se ter claro, no entanto, que a discussão travada por ambos é mais abrangente que a apresentada aqui. Portanto, muitas de suas particularidades acabaram ficando de fora.

Por fim, deve-se concluir que o debate conduzido por esses autores possibilitou, de uma maneira geral, elucidar vários elementos singulares da organização eleitoral e política brasileiro da época. Não é por menos que Santos termina o seu artigo declarando que Alencar "surge como um dos mais sofisticados teóricos da democracia, escrevendo no século XIX" (SANTOS, 1991:51).

\section{BIBLIOGRAFIA}

ALENCAR, José. Systema representativo e reforma eleitoral. In: SANTOS, Wanderley Guilherme dos. Dois Escritos Democráticos de José de Alencar: Sistema Representativo, 1868; Reforma Eleitoral, 1874. Rio de Janeiro: Editora da UFRJ, 1991.

Anais do Senado do Império do Brasil. Rio de Janeiro: Typographia do Correio Mercantil, 1860. Sessão de 1860, v. IV.

MILL, John Stuart. 0 governo representativo. Brasília: Editora Universidade de Brasília, 1981.

RIZZO, Ricardo M artins. Entre deliberação e hierarquia: Uma leitura da teoria Política de José de Alencar (1829-1877). 2007. Dissertação (Mestrado em Ciência Política) Faculdade de Filosofia, Letras e Ciências Humanas da Universidade de São Paulo, São Paulo, 2007.

SANTOS, Wanderley Guilherme dos. A teoria da democracia proporcional de José de Alencar. In: Dois Escritos Democráticos de José de Alencar: Sistema Representativo, 1868; Reforma Eleitoral, 1874. Rio de Janeiro: Editora da UFRJ, 1991. SOUZA, Francisco Belisário Soares de. 0 sistema eleitoral no império. Brasília: Senado Federal: Editora da Universidade de Brasília, 1979.

TOCQUEVILLE, Alexis de. A democracia na América. Belo Horizonte: Editora Itatiaia; São Paulo: Edusp, 1987.

Artigo recebido em 28 de julho de 2014.

Aprovado em 31 de março de 2015. 